\title{
Exploration of Antibacterial Activities of Berberis royleana Fractions Extracts
}

By

MUHAMMAD RAFIQUE ${ }^{1}$ and Dr. MUHAMMAD SALMAN ${ }^{2}$

1. Faculty of Life Sciences Department of Microbiology and Biotechnology, Abasyn University Peshawar

2. Faculty of Life Sciences Department of Microbiology and Biotechnology, Abasyn University Peshawar

\section{Faculty of Life Sciences,}

Abasyn University Peshawar Campus,

Ring Road (Charsadda Link), Peshawar, Khyber

Pakhtunkhwa 


\title{
Exploration of Antibacterial Activities of Berberis royleana Fractions Extracts By
}

\author{
MUHAMMAD RAFIQUE ${ }^{1}$ and Dr. MUHAMMAD SALMAN ${ }^{2}$
}

1. Faculty of Life Sciences Department of Microbiology and Biotechnology, Abasyn University Peshawar 2. Faculty of Life Sciences Department of Microbiology and Biotechnology, Abasyn University Peshawar

\begin{abstract}
Objectives: Prepare various solvent extracts of Berberis royleana (areal part of plant) to determine the in vitro antibacterial potential of methanolic, ethyl acetate, chloroform, $n$-hexane and water extracts of $B$. royleana against various bacterial isolates and Compare the efficacy of outstanding antimicrobial extracts of $B$. royleana with commonly used antibiotics. Berberis species are medicinally important plants, produce various metabolites and used as treatment for multiple complications. Berberis royleana is a rare specie belongs to genus Berberis.

Methods: In the current study the areal parts of the plant were isolated to explore antibacterial activities. Antibacterial activities were done using standard procedures. The antibacterial activities of different fractions were tested by $100 \mu \mathrm{g}$ methanolic, ethyl acetate, chloroform, $n$-hexane and water fractions of $B$. royleana against bacterial isolates Escherichia coli, Staphylococcus aureus, Klebsiella pneumoniae, Pseudomonas aeruginosa, Salmonella Typhi and Proteus spp. The ciprofloxacin $(5 \mu \mathrm{g})$ was used as a positive control and DMSO as a negative control.

Results: All fractions showed zone of inhibition against the growth of tested bacterial isolates. Methanolic fractions have maximum ZI against $S$. aureus and $K$. pneumoniae $(25.7 \pm 1.5 \mathrm{~mm})$, S. aureus $(23 \pm 2.7)$, Salmonella Typhi (25 \pm 1$)$, water fraction have Klebsiella pneumoniae (24.4 \pm 2.5$)$, Salmonella Typhi (23 $\pm 1 \mathrm{~mm}), S$. aureus $(21 \pm 2.8 \mathrm{~mm})$ and the $n$-hexane fraction exhibits ZI against $K$. pneumoniae $(24.7 \pm 1.5)$, Salmonella Typhi $(24 \pm 2)$ S. aureus, ethyl acetate maximum zone against E. coli $(16.6 \pm 3.1)$ and chloroform fraction showed maximum ZI against $S$. Typhi (21.6 \pm 3.3$)$.

Conclusion: From current report it may be concluded that B. royleana extracts have medicinally effective potentials against drugs resistant bacteria.
\end{abstract}




\section{INTRODUCTION}

Multiple antimicrobial agents show resistance in pathogenic bacteria which become an important public health problems. For treatment of infection there are rare, or even sometimes no effective antimicrobial agents available. This justifies the exploration of alternative forms for the treatment of infections, such as novel compounds with bactericidal properties from natural sources like plants [1] [2]. The crude extracts of plant segments and phytochemicals of identified antimicrobial properties have importance in therapeutic cure [3]. The infectious microorganism have shown resistance to several antimicrobial agents due to environmental advancement and for this purpose new antimicrobial drugs are needed from time to time treat disease [4].

\subsection{Medical uses of medicinal plants}

The practice of traditional medicine is widespread in Pakistan, Japan, China, India, Sri Lanka and Thailand [5] [6] [7]. For treatment and curing of various human diseases and infections used variety of plant and different parts of plant are used in traditional medicine which is one of the oldest systems of world [8] [9] [10].

\subsubsection{Medicinal Plant against Bacterial Infection}

The bacterial resistance is rising a problem and the perspective of the use of antimicrobial drugs in the future is extremely uncertain. Many pathogens cause diseases shows resistant to antibiotics as a result cause illness, death and an even huge economical loss [11]. Increasing levels of antibiotic resistance in pathogenic bacteria has increased the demand to search novel antibiotics for diseases control. In mid- $21^{\text {st }}$ century due to the drug resistant there are millions of deaths occurred and also loss of trillions of dollars in recent reports [1]. The rise of antimicrobial resistance show in bacteria. The Gram-positive bacteria mostly cocci like coagulase-negative Staphylococcus aureus, Enterococcus and staphylococci species are crucial microorganisms in the hospital atmosphere [2] [12]. In the Enterobacteriaceae family Gramnegative bacteria are significant causes of urinary tract infections (UTIs), pneumoniae, invasive and various peritoneal infections. $K$. pneumoniae is second most causative pathogens which causing invasive infection after the Escherichia coli. A major resistance problem in Enterobacteriaceae infections are production of extended-spectrum b-lactamases (ESBLs) (David et al., 2006; [13].

\subsubsection{Escherichia coli}

Escherichia coli (E. coli) is involved in both commensals and pathogenic strains of the gastrointestinal tracts of vertebrates which is causative pathogen for multiple extra and intra intestinal infections [14].

\subsubsection{Pseudomonas aeruginosa}

Pseudomonas aeruginosa ( $P$. aeruginosa) is a cosmopolitan Gram-negative aerobic bacillus, mainly nosocomial pathogen [15]. P. aeruginosa most common pathogen isolated from surgical site infection, invasive infection, nosocomial pneumonia, urinary tract infection (UTIs) [16]. P. aeruginosa caused diverse diseases which are existence of multiple pathogenic mechanisms must be expected [17]. In United States the $P$. aeruginosa bacteria are common cause of morbidity and also cause mortality in hospitalized patients [18]. 


\subsubsection{Klebsiella pneumoniae}

Klebsiella pneumoniae (K. pneumoniae) is a Gram- negative bacteria, Cylindrical in shape and rod like. It is of about 2 microns in length and 0.5 microns in diameter and widely distributed in nature, found abundantly in soil and water [19]. K. pneumoniae is among the most common pathogenic bacteria and hospital-acquired pathogen which causing urinary tract infections (UTIs), pneumonia and peritoneal infection in hospitalized immune compromised patients with severe underlying diseases. It was also a possible community acquired pathogen and second only to E. coli in gram negative bacteria [20] [13]. Multiple antimicrobial agents are increasingly resistant to $K$. pneumoniae isolate which are including Quinolones and production of extended-spectrum Cephalosporins (ESC) extended-spectrum betalactamases (ESBL) such as Ceftazidime [21].

\subsubsection{Salmonella}

In several countries resistant reported in salmonella species to expanded-spectrum Cephalosporins. Salmonella infections that occur in United States each year about 1.4 million and most are in the elderly, children and approximately 600 are fatal [22] [23].

\subsubsection{Proteus}

Proteus species belong to family Enterobacteriaceae a bacillus which is Gram negative bacteria and also serious cause of infection in human [24]. Proteus species among those pathogens which can cause both community and hospital acquired infections. Because different mode of transmission it can causes various type of infection in human. Source of infection contaminated water, soil, food, equipment, catheters, intra venous lines, the hands of patients and health staff [25].

\subsubsection{Staphylococcus aureus}

Staphylococcus aureus (S. aureus) is a commensal organism in human being which carried in the nares of $30 \%$ of healthy adults. S. aureus can colonize and cause a variety of supporative diseases in man including skin, blood, wound sites, bone infections and vascular catheters as well as the nasopharynx in the hospitalized patients [26] [27]. S. aureus is a hospital acquired diseases, serious community and a major problem of Public health [28].

\subsection{Berberis royleana}

Berberis royleana (B. royleana) is rare species amongst the members of Berberis (Berberidaceae). This specie is still imperfectly known and the flower is not specified. It differs from other species of the genus by its smaller leaves, narrow fruits, inflorescence and pedicels. B. royleana is a deciduous plant with height up to $3 \mathrm{~m}$. The roots are thick and broaden easily. The stem has red-brown color and has spines. Leaves are usually 7-15 mm long, 6-12 mm broad. The ripe fruit is ovoid with red color and about $1 \mathrm{~cm}$ in length. The fruits developed in clusters form are bitter to taste. Berries are somewhat black, pruinose grey, oblong, $8 \mathrm{~mm}$ long and $3.5 \mathrm{~mm}$ broad immature [29].

\subsubsection{Medicinal uses of Genus Berberis}


Berberis have been supportive within cure of malignancy, diabetes, jaundice, spleenomegaly, AIDS, arthritis, cardiac diseases, eye infections, hypertension, infectious diseases, cholera, diarrhea, wounds, intestinal colic, dysentery, amoebiasis, eye troubles, leprosy, antimalaric, anti-inflammatory, fever, inflammation (swelling), gastric pain, UTI infection, throat infection, gums infections [30][11][31] [32].

\subsubsection{Properties of Berberis}

The roots of Berberis species are working as an anti-periodic, diaphoretic and antipyretic and its action was supposed to be as powerful as quinine. The shoot is used as a tonic, anti-periodic, cardiovascular, hepato-protective, antimicrobial and anti-cancerous activities [33].

\section{METERIAL AND METHOD}

\subsection{Study area}

This study were carried out in Microbiology and Biotechnological Department Abasyn University Peshawar from February 2018 to July 2018.

\subsection{Collection and identification}

The Disease free Berberis royleana plant was collected from Azad Kashmir, Pakistan. The plant specimen was identified by Dr. Taj Ur Rahman, Department of chemistry Mohi-Ud-Din Islamic University Azad Jammu \& Kashmir.

\subsection{Sample preparation}

The areal part of B. royleana plant was washed with distilled water. The B. royleana were air-dried at room temperature under shade. The plant was collected and powder was made by using electric grinder. The powder samples of plant were then packed in clear polythene pouches, sealed and stored at room temperature.

\subsection{Preparation of crude extract of $B$. royleana}

One kilograms powder of $B$. royleana was dissolved in $1000 \mathrm{ml}$ methanol and kept at room temperature for 7 days. The mixture was intervally shaked to get maximum extract. The methanol soluble components was filtered using Whattman filter paper stored in container and the process was repeated for another 7 days. The extracts were collected from both containers and combined. The extract solution was dried using a vacuum pump with the rotary evaporator with reduced pressure at a temperature of $45^{\circ} \mathrm{C}$. The remaining methanol are evaporated at $45^{\circ} \mathrm{C}$ in water bath. The semi-solid crude extract was obtained and kept in sterile bottles at $4^{\circ} \mathrm{C}$ until use.

\subsection{Fractionation}

About 55 grams of crude extract of B. royleana suspended in $200 \mathrm{ml}$ distilled water and shaked with help of electromagnetic shaker. Methanolic crude extract was dissolved completely in distilled water and pour 
in separatory funnel. For further fractionation different solvents was added into the mixture. I.e. $n$-hexane, ethyl acetate and chloroform [34] [35].

\subsection{Stock concentration of extracts}

All B. royleana fractions (methanol, water, $n$-hexane, ethyl acetate and chloroform) are were dissolved in $10 \mathrm{mg} / 1 \mathrm{ml}$ dimethyl sulfoxide (DMSO) solution for further use.

\subsection{Control}

Ciprofloxacin $(5 \mu \mathrm{g})$ antibiotic was used as a positive control for both Gram positive and Gram negative bacterial isolates. Dimethyl sulfoxide (DMSO) solution was used as a negative control for antibacterial.

\subsection{Isolation of tested microorganisms}

\subsubsection{Bacterial isolates}

The different bacterial isolates were used in the study such as Staphylococcus aureus, Escherichia coli, Salmonella Typhi, Pseudomonas aeruginosa, Klebsiella pneumoniae and Proteus spp. All the bacterial isolates were clinically obtained from Lady Reading Hospital (LRH) Peshawar, Hayatabad Medical Complex MTI (HMC) and MMC General Hospital Peshawar Khyber Pakhtunkhwa, Pakistan. Bacterial isolates were sub cultured on nutrient agar medium and incubated at $37^{\circ} \mathrm{C}$ for 24 hours. The Broth of each bacterium was prepared from developed ( 24 hours) culture of bacteria on nutrient agar.

\subsection{Antibacterial activity}

\subsubsection{Preparation of nutrient agar and sampling}

Sterilization of glass wares was done through steam sterilization using autoclave. Culture media was prepared in conical flask having distilled water using standard protocol. Nutrient agar $(28 \mathrm{~g})$ was dissolve distilled water made up volume up to $1000 \mathrm{ml}$ followed by autoclaving at $121{ }^{\circ} \mathrm{C}$ for $15 \mathrm{~min}$. The media was cooled upto $45^{\circ} \mathrm{C}$ and poured into sterile Petri dishes and allowed to solidify at room temperature.

\subsubsection{Antibacterial activity of Berberis royleana extract}

Antibacterial activity of the crude extracts was checked using agar well diffusion method by Aliakbarlu et al., 2014 [36]. Mueller-Hinton agar (38 g) was dissolve in distilled water made up volume $1000 \mathrm{ml}$ and autoclaved. The autoclaved Mueller-Hinton agar was poured in Petri dishes and allowed to solidify for 30 minutes. Mueller-Hinton agar plates were kept in Laminar Flow Hood and bacterial culture (Staphylococcus aureus, Escherichia coli, Salmonella Typhi, Pseudomonas aeruginosa, Klebsiella pneumoniae and Proteus spp) was inoculated using sterile cotton swabs to achieve uniform lawn of growth. Wells of $6 \mathrm{~mm}$ in diameter and about $20 \mathrm{~mm}$ apart were punctured in the culture media using sterile cork borers to make three to five uniform wells in each Petri dish. A drop of molten nutrient agar was used to seal the base of each well. The $100 \mu \mathrm{g}$ of each fraction of B. royleana plant extract (methanol, water, $n$ - hexane, ethyl acetate, chloroform) was introduced through micropipette aseptically into specifically marked wells in the agar plates and the antibiotic (Ciprofloxacin $5 \mu \mathrm{g}$ ) was used as positive 
control for specific bacteria and dimethyl sulfoxide (DMSO) as a negative control. The plates were kept undisturbed for 45 minutes to make the free diffusion of the extract. The antibacterial activities were observed after 24 hours of incubation at $37^{\circ} \mathrm{C}$. The zone of inhibition by fraction extracts of B. royleana, positive and negative controls were measured $(\mathrm{mm})$ and snapshots of inhibitory zone of all bacterial isolates were saved.

\section{RESULTS}

\subsection{Berberis royleana Extracted materials}

The dried powder of crude methanol extracts obtained after filtration and rotary evaporation about 106 grams powder was found. Different solvents extracts were obtained after fractionation i.e. water fraction $(55 \mathrm{~g}), n$ - hexane fraction $(0.7 \mathrm{~g})$, Ethyl acetate fraction $(12 \mathrm{~g})$ and chloroform $(13 \mathrm{~g})$ and $10 \mathrm{gm}$ crude methanol extract was already stored.

\subsection{Antibacterial activity of Berberis royleana Extract}

Antibacterial activity of $100 \mu \mathrm{g} B$. royleana each (methanol, water, ethyl acetate, $n$-Hexane and chloroform) fraction extracts against 42 bacterial isolates showed decent activity against each bacterial isolates such bacterial isolates are S. aureus (16), E. coli (13), K. pneumoniae (3). P. aeruginosa (4), Proteus spp (3) and S. Typhi (3) which showed different zone of inhibitions (Table 4.2).

\subsubsection{Antibacterial activity of methanolic fraction}

Hundred (100) $\mu \mathrm{g}$ of B. royleana methanolic extract showed maximum zone of inhibition (ZI) against $K$. pneumoniae i.e. $25.7 \mathrm{~mm}$ ( $\mathrm{SD} \pm 1.5$ ), while minimum ZI was found against Proteus spp $16.7 \mathrm{~mm}$ (SD \pm 3.21 ). The detailed description against all bacterial isolates is mentioned in Table 4.3. The results of methanolic extract against bacterial isolates have been compared with positive control (Ciprofloxacin 5 $\mu \mathrm{g}$ ) as shown in figure 4.1. The DMSO was used as negative control.

\subsubsection{Antibacterial activity water fraction}

Hundred (100) $\mu \mathrm{g}$ of B. royleana water fraction showed maximum zone of inhibition (ZI) against $K$. pneumoniae i.e. $24.4 \mathrm{~mm}$ ( $\mathrm{SD} \pm 2.5$ ), while minimum ZI was found against Proteus spp $15 \mathrm{~mm}(\mathrm{SD} \pm 2.6)$. The detailed description against all bacterial isolates is mentioned in Table 4.4. The results of water extract against bacterial isolates have been compared with positive control (Ciprofloxacin $5 \mu \mathrm{g}$ ) as shown in figure 4.2. The DMSO was used as negative control.

\subsubsection{Antibacterial activity $n$ - Hexane fraction}

Hundred (100) $\mu \mathrm{g}$ of $B$. royleana $n$-hexane fraction showed maximum zone of inhibition (ZI) against $K$. pneumoniae i.e. $24.7 \mathrm{~mm}(\mathrm{SD} \pm 1.5$ ), while minimum ZI was found against Proteus spp $14 \mathrm{~mm}(\mathrm{SD} \pm 3$ ). The detailed description against all bacterial isolates is mentioned in Table 4.5. The results of $n$-hexane fraction against bacterial isolates have been compared with positive control (Ciprofloxacin $5 \mu \mathrm{g}$ ) as shown in figure 4.3. The DMSO was used as negative control. 


\subsubsection{Antibacterial activity of Ethyl acetate fraction}

Hundred (100) $\mu \mathrm{g}$ of B. royleana ethyl acetate fraction showed maximum zone of inhibition (ZI) against E. coli i.e. $16.6 \mathrm{~mm}$ (SD \pm 3.1 ), while minimum ZI was found against Proteus spp $12.7 \mathrm{~mm}(\mathrm{SD} \pm 2.5)$. The detailed description against all bacterial isolates is mentioned in Table 4.6. The results of ethyl acetate fraction against bacterial isolates have been compared with positive control (Ciprofloxacin $5 \mu \mathrm{g}$ ) as shown in figure 4.4. The DMSO was used as negative control.

\subsubsection{Antibacterial activity of chloroform fraction}

Hundred (100) $\mu \mathrm{g}$ of B. royleana chloroform fraction showed maximum zone of inhibition (ZI) against $S$. Typhi i.e. $21.6 \mathrm{~mm}$ (SD \pm 3.3 ), while minimum ZI was found against Proteus spp $13.3 \mathrm{~mm}$ (SD \pm 3.4 ). The detailed description against all bacterial isolates is mentioned in Table 4.7. The results of chloroform fraction against bacterial isolates have been compared with positive control (Ciprofloxacin $5 \mu \mathrm{g}$ ) as shown in figure 4.5. The DMSO was used as negative control.

\section{DISCUSSION}

Microbial resistance is one of the major health issue in developing countries. Most of the bacterial and fungal species developed resistance to available drugs. An alternative remedy is essential to prevent this drug resistance as well as it should be cost effective. In current study examine the potential antimicrobial activity of methanolic, ethyl acetate, chloroform, n-hexane and water extracts of $B$. royleana against bacterial and fungal species by means of the whole plate and disc diffusion methods in order to compare the suitability of the identification methods and in vitro insecticidal activity of methanolic, ethyl acetate, chloroform, $n$-Hexane and water fraction extracts of $B$. royleana against insects by direct contact application and of all the activities of the extracts.

\subsection{Antibacterial activity of methanolic fraction}

In current research, $100 \mu \mathrm{g}$, methanolic fraction of Berberis royleana extract showed maximum ZI against K. pneumoniae as i.e. $25.7 \mathrm{~mm}(\mathrm{SD} \pm 1.5)$ while that of minimum was against Proteus spp. i.e. $16.7 \mathrm{~mm}$ (SD \pm 3.21 ) followed by $S$. Typhi $25 \mathrm{~mm}(\mathrm{SD} \pm 1)$ and $S$. aureus $23 \mathrm{~mm}(\mathrm{SD} \pm 2.7)$ P. aeruginosa $21.5 \mathrm{~mm}$ (SD \pm 5.1 ) and E. coli $20.62 \mathrm{~mm}(\mathrm{SD} \pm 3.4$ ). In similar report the crude methanolic extract Berberis baluchistanica showed antimicrobial activities against Klebsiella pneumoniae 12.67 (SD \pm 0.76$)$, S. aureus

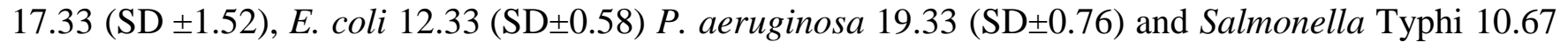
$(\mathrm{SD} \pm 1.04)$ [37]. Another research methanolic extract reveals ZI against E. coli $(15 \mathrm{~mm})$, K. pneumoniae $(16 \mathrm{~mm})$ and some pathogens are resistant i.e. S. aureus [38]. In another investigation methanolic root extracts of Berberis lycium exhibited maximum inhibitory zone E. coli (12 mm), Pseudomonas spp (11 $\mathrm{mm})$, Staphylococcus spp $(10 \mathrm{~mm})$ [39]. In study Rasool et al., 2015 the antibacterial activity of methanol extract of $B$. calliobotrys against $S$. aureus $(27 \pm 2.51)$ and $P$. aeruginosa $(20 \pm 3)$ and results compared with ciprofloxacin [40]. Our studies are agreement with Kakar et al., 2012 [37]. In current studies and the previous studies of (Rasool et al., 2015[38] [39] [40]) have good activity against bacterial species (gram negative and gram positive) with comparison of standard antibiotics but the some difference between both studies different number of bacterial isolates and used of different volume of concentrations.

\subsection{Antibacterial activity of water fraction}


In current research, $100 \mu \mathrm{g}$, water fraction of Berberis royleana extract showed maximum ZI i.e. 24.4 (SD \pm 2.5 ) against $K$. pneumoniae while minimum ZI was 15 (SD \pm 2.6 ) against Proteus spp followed by $S$. Typhi $23(\mathrm{SD} \pm 1$ ) and $S$. aureus $21(\mathrm{SD} \pm 2.8)$, E. coli $18.9(\mathrm{SD} \pm 4)$ and $P$. aeruginosa 18.5 (SD \pm 3.8$)$. In similar study the water fraction of Berberis aristata extract showed no activity against Klebsiella

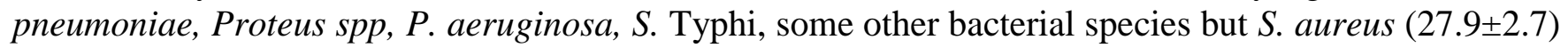
showed good activity [41]. In previous study of Malik et al., 2017 the aqueous extract showed antimicrobial activity against Berberis artista showed highest zone of inhibition for E. coli (10.0 \pm 1.3$)$ followed by $S$. typhimurium $(9.3 \pm 0.1)$ and $S$. aureus $(8.3 \pm 1.7)$ [42]. In previous study of Dashti et al., 2014 the aqueous extracts of the fruits of berberis showed antimicrobial activity against $S$. aureus ZI (11 $\pm 0.87)$ and $E$. coli $(10 \pm 0.87)$ [43]. Our results showed significant activity against all bacterial isolates as compare to previous studies [41] [42] [43] the reason may be isolation of the bacteria from different body sites and plant species. In present we found that previous studies have similar procedure but the plant species are different from the present study and different concentrations of extract are used against bacterial species and different standard drug.

\subsection{Antibacterial activity of $\boldsymbol{n}$ - Hexane fraction}

In current study, $100 \mu \mathrm{g}, n$-Hexane fraction of Berberis royleana extract showed maximum ZI i.e. 24.7 ( $\mathrm{SD} \pm 1.5$ ) against $K$. pneumoniae while that of minimum was against Proteus spp. i.e. 14 (SD \pm 3 ) followed by $S$. Typhi 24 (SD \pm 2 ), P. aeruginosa 22.5 ( $\mathrm{SD} \pm 1$ ) and $S$. aureus 20.1 ( $\mathrm{SD} \pm 4.2$ ). In similar study Shah et al., 2012 analyzed for antibacterial activities, $n$-Hexane extract of Berberis vulgaris was exhibited no significant activity against the Staphylococcus aureus, Klebsiella pneumonia and Escherichia coli [4]. In Aziz et al., 2011 study of Vitex agnus-castus hexane fraction demonstrated antibacterial activity against B. cereus $(7.5 \mathrm{~mm})$, P. aeruginosa $(10 \mathrm{~mm})$ and $S$. Typhi $(11 \mathrm{~mm})$ while other Corynebacterium diptheriae, E. coli, K. pneumoniae, Proteus mirabills and S. aureus show resistant [44]. Current research have significant activities against both Gram negative and gram positive bacterial isolates but the pervious [4] [44] studies there are some bacterial isolates were inactive to plant extract. There are same procedure and same fraction were used in previous studies as compared with present study.

\subsection{Antibacterial activity Ethyl acetate fraction}

In current study, $100 \mu \mathrm{g}$, ethyl acetate fraction of Berberis royleana extract showed maximum ZI i.e. 16.6 (SD \pm 3.1 ) against $E$. coli while that of minimum ZI i.e. 12.7 ( $\mathrm{SD} \pm 2.5$ ) against Proteus spp followed by $K$. pneumoniae 16.3 (SD \pm 1.5 ) and $S$. aureus $16.2(\mathrm{SD} \pm 2.8)$ and $P$. aeruginosa $14(\mathrm{SD} \pm 1.6)$. In similar study the ethyl acetate fraction extract of Berberis baluchistanica showed no activity against $K$. pneumoniae, Proteus and other bacterial species [45]. Another research reveals ZI against E. coli (15 mm), $K$. pneumoniae $(16 \mathrm{~mm})$ and some pathogens are resistant i.e. S. aureus [38]. Our results showed significant activity against all bacterial isolates as compare with [45], the reason may be isolation of the bacteria from different body sites and plant species. Our studies are agreement with Sasikumar et al. 2007 [38]. Both reports have similar procedure but the plant species are different from the present study and different concentrations $(10,5,2.5 \mathrm{mg} / \mathrm{ml})$ of ethyl acetate extract was used against bacterial species and different standard drug.

\subsection{Antibacterial activity Chloroform fraction}


In present investigation, $100 \mu \mathrm{g}$ Chloroform fraction of Berberis royleana extract demonstrated maximum ZI i.e. 21.6 (SD \pm 3.3 ) against $S$. Typhi followed by K. pneumoniae 21.3 (SD \pm 3.3 ), P. aeruginosa 20.7 (SD \pm 3.4 ), S. aureus 19.7 (SD \pm 3.34 ), E. coli 18.5 (SD \pm 4.65 ) and minimum against Proteus spp 13.3 (SD $\pm 3.51)$. In the [38] studies the chloroform root extracts of $B$. tinctoria exhibited maximum activity against $P$. aeruginosa $(25 \mathrm{~mm})$, K. pneumoniae $(20 \mathrm{~mm})$, E. coli $(10 \mathrm{~mm})$, Salmonella species $(20 \mathrm{~mm})$, S. aureus $(15 \mathrm{~mm})$, A. hydrophila $(15 \mathrm{~mm})$ and other pathogens $V$. cholera and $V$. parahemolyticus were resistant. In study of [44] the chloroform fraction of Vitex agnus-castus exhibited ZI against K. pneumoniae (8 mm), $P$. aeruginosa $(6.5 \mathrm{~mm})$ and $S$. typhi $(10 \mathrm{~mm})$ while Corynebacterium diptheriae, E. coli, K. pneumoniae, P. mirabills and $S$. aureus show resistant. In previous investigation of Baloch et al., 2013 Chloroform fraction of Thuspeinanta brahuica root showed strong activity against $B$. subtilis $(28 \mathrm{~mm})$ and moderate activity against $S$. aureus with $(25 \mathrm{~mm})$ of zone inhibition. E. coli showed (14 $\mathrm{mm})$ of zone inhibition, $S$. Typhi showed $(12 \mathrm{~mm})$ of zone inhibition whereas $P$. aeruginosa was resistant to chloroform fraction [46]. Our studies are in agreement with [38]. In present study significant activities against all bacterial isolates were found, as compared to previous studies [44] [46] where some extracts showed activities, however, some of them were inefficient against resistant bacterial species. The reason may be geographical distribution, site of sample collection.

\section{CONCLUSIONS AND RECOMMENDATIONS}

\section{CONCLUSIONS}

Antimicrobial activities of Berberis royleana methanol and water fractions showed promising results as compared to chloroform, ethyl acetate and n-hexane the maximum ZI against $S$. aureus, E. coli, S. Typhi, $P$. aeruginosa, $K$. pneumoniae recorded was $25.7 \pm 1.5 \mathrm{~mm}$ while these extract showed minimum ZI against Proteus spp from $16.7 \pm 3.21 \mathrm{~mm}$.

From current report it may be concluded that $B$. royleana extracts have medicinally effective potentials against drugs resistant bacteria.

\section{RECOMMENDATIONS}

1. Fourier Transform Infrared Radiation (FTIR) and Gas Chromatographic Mass Spectroscopy (GCMS) analysis are highly recommended to explore the active chemicals in B. royleana.

2. The nanoparticles may be prepared using B. royleana to test against MDR bacteria.

\section{REFRANCES}

[1] Tayung K, Barik B, Jha D, \& Deka D C. Identification and characterization of antimicrobial metabolite from an endophytic fungus , Fusarium solani isolated from bark of Himalayan yew. Mycosphere, 2011; 2(3), 203-213.

[2] Magiorakos A, Srinivasan A, Carey R B, Carmeli Y, Falagas M E, Giske C G, Hindler J F. Bacteria : an International Expert Proposal for Interim Standard Definitions for Acquired Resistance. Microbiology, 2011; 18(3), 268-281.

[4] Shah Z, Ilyas M, Khan M, Ahmad A, Khan M, \& Khan N. Antimicrobial activities of selected 
medicinal plants collected from Northern districts of Khyber Pakhtunkhwa , Pakistan. Journal of Pharmacy Research, 2012; 5(3), 1729-1733.

[5] Amin A, \& Ayaz K M. In vitro bactericidal and bacteriostatic potential of ingridients of traditional medicine obtained from Kacha area (River Indus) district D.I.Khan, KPK, against human bacterial pathogens. Pakistan Journal of Botany, 2011; 43(5), 2613-2617.

[6] Sarwat S Z, \& Ahmad N. Screening of potential medicinal plants from district swat specific for controlling women diseases. Pak J Bot, 2012; 44(4), 1193-8.

[8] Ekpo M A, and Etim P C. Antimicrobial activity of ethanolic and aqueous extracts of Sidaacuta on microorganisms from skin infections. Journal Med. Pl. 2009; 3(9): 621-624.

[7] Venkatesan D, Karrunakaran C M, and Selva K S. Studies on phytochemical constituents, functional group identification and antimicrobial activity of Solanum nigrum (Solanaceae). Ethnobotanical Leaflets, 2009; 13:1485-1503.

[9] Vineela C H. and Elizabeth K M. Antimicrobial activity of marine algae of Visakhapatnam City, Andhra Pradesh. Asian Journal of Microbiological Biotechnological Environmental Science, 2005; 7: 209-212.

[10] Nweze E L, Okafor J I, and Njokn O. Antimicrobial activities of methanolic extracts of Tremaguineense (Schumach. and Thonn.) Ficalho and Morindalucida Benth. used in Nigeria. Biological journal. 2004; 2:39-46.

[11] Claudia M M, Sara E S, Virginia J, Diego C, C. T. \& A. L. L. Antibacterial activity study of single and combined extracts of Berberis ruscifolia, Baccharis sagittalis, Euphorbia dentata and Euphorbia schikendanzii, native plants from Argentina, 2012.

[12] Rice L B. Antimicrobial resistance in gram-positive bacteria. The American Journal of Medicine, 2006; 119 (6A), 1555-7162.

[13] Tumbarello M, Spanu T, Sanguinetti M, Citton R, Montuori E, Leone F, Cauda R. Bloodstream Infections Caused by Extended-Spectrum-Betalactamase-Producing Klebsiella pneumoniae: Risk Factors , Molecular Epidemiology, and Clinical Outcome. American Society for Microbiology, 2006; 50(2), 498504.

[14] Shaheen A Y, Sheikh A A, Rabbani M, Aslam A T B, Liaqat F, Muhammad J, and Rehmani S F, Antibacterial activity of herbal extracts against multi-drug resistant Escherichia coli recovered from retail chicken meat. Pakistan Journal of Pharmaceutical Sciences, 2015; 28(4), 1295-1300.

[15] Kinska D L, and Guilligan P H. Pseudomonas. In: Murray P, ed. Manual of clinical microbiology. Washington, DC: ASM Press. 1999; 1999:517-25.

[16] Gales A, Jones R N, Turnidge J, Rennie R, \& Ramphal R. Characterization of Pseudomonas aeruginosa isolates: occurrence rates, antimicrobial susceptibility patterns, and molecular typing in the 
global Sentry Antimicrobial Surveillance Program, 1997-1999. Clinical Infectious Diseases, $2001 ; 32$ Suppl 2(1058-4838), S146-S155.

[17] Pollack M, Mandell G L, Bennett J E, Dolin R. Pseudomonas aeruginosa. Principles and practice of infectious diseases, 2000; 2:2310-35.

[18] McGowan J E. Resistance in nonfermenting gram-negative bacteria: Multidrug resistance to the maximum. The American Journal of Medicine, 2006; 119(6A), S29-S36 Resistance.

[19] Shaik G, Sujatha N, \& Mehar S K. Medicinal plants as source of antibacterial agents to counter Klebsiella pneumoniae. Journal of Applied Pharmaceutical Science, 2014; 4(1), 135-147.

[20] ChienKo W, Paterson D L, Sagnimeni A J, Hansen D S, Von Gottberg A, Mohapatra S, Yu V L. Community-acquired Klebsiella pneumoniae bacteremia: Global differences in clinical patterns. Emerging Infectious Diseases, 2002; 8(2), 160-166.

[21] Woodford N, Turton J F, \& Livermore D M. Multiresistant Gram-negative bacteria: The role of highrisk clones in the dissemination of antibiotic resistance. FEMS Microbiology Reviews, 2011; 35(5), 736755.

[22] Paul D E, Safranek T J, Rupp M E, Dunne E F, Ribot E, Iwen P C, Angulo A, and Steven H, Ceftriaxone-resistant salmonella infection acquired by a child from cattle. The New England Journal of Medicine, 2000; 342(17), 1242-1249.

[23] Mermin J, Hutwagner L, Vugia D, Shallow S, Daily P, Bender J, Angulo F J. Reptiles, Amphibians, and Human Salmonella Infection: A Population-Based, Case-Control Study. Source Clinical Infectious Diseases, 2004; 38(3), 253-261.

[24] Bradford P A. Extended spectrum betalactamase in the 21 century: characterization, epidemiology, and detection of this important resistant threat. Clinical Microbiol Rev, 2001; 14(4), 933-951.

[25] Feglo P K, Gbedema S Y, Quay S N A, Adu-Sarkodie Y, \& Opoku-Okrah C. Occurrence, species distribution and antibiotic resistance of Proteus isolates: A case study at the Komfo Anokye Teaching Hospital (KATH) in Ghana. Int J Pharm Sci Res, 2010; 1(9), 347-52.

[26] Huang S S, \& Platt R. Risk of methicillin-resistant Staphylococcus aureus infection after previous infection or colonization. Clinical Infectious Diseases, 2003; 36(1537-6591), 281-285.

[27] Saha B, Singh A K, Ghosh A, \& Bal M. Identification and characterization of a vancomycin-resistant Staphylococcus aureus isolated from Kolkata (South Asia). Journal of Medical Microbiology, 2008; 57(1), 72-79.

[28] Pereira V, Lopes C, Castro A, Silva J, Gibbs P, \& Teixeira P. Characterization for enterotoxin production, virulence factors, and antibiotic susceptibility of Staphylococcus aureus isolates from various foods in Portugal. Food Microbiology, 2009; 26(3), 278-282. 
[29] Jafri S M H. Berberidaceae. Printed at Ferozsons. Flora of Pakistan. Ahrendt in J. Asiat. Soc. Beng. (Sc.). In J. Linn. Soc. Bot 197511 (5), 1945.57:227.1961.

[30] Khan T, Ahmed I K, Rehman A, and khan R. Spatial distribution of genus Berberis from Pakistan : A review over three centuries long historical records. Spatial distribution of genus Berberis from Pakistan :A review over three centuries long historical records 2015.

[31] Manosalva L, Mutis A, Urzua A, Fajardo V, \& Quiroz A. Antibacterial activity of alkaloid fractions from Berberis microphylla G. Forst and study of synergism with ampicillin and cephalothin. Molecules, 2016; 21(1), 1-10.

[32] Malik T A, Kamili A N, Chishti M Z, Ahad S, Tantry M A, Hussain P R, \& Johri R K. Breaking the resistance of Escherichia coli: Antimicrobial activity of Berberis lycium Royle. Microbial Pathogenesis, 2017; 102, 12-20.

[33] Srivastava S, Srivastava M, Misra A, Pandey G, \& Rawat A. A review on biological and chemical diversity in Berberis (Berberidaceae). EXCLI Journal, 2015; 14(1611-2156), 247-267.

[34] Alamgeer A H, \& Rasool S. Antithrombotic potential of Berberis calliobotrys extract. Bangladesh Journal of Pharmacology, 2016; 11(4), 776.

[35] Bibi Y, Nisa S, Chaudhary F M, \& Zia M. Antibacterial activity of some selected medicinal plants of Pakistan. BMC Complementary and Alternative Medicine, 2011; 11(52), 2-7.

[36] Aliakbarlu J, Mohammadi S, \& Khalili S. A study on antioxidant potency and antibacterial activity of water extracts of some spices widely consumed in Iranian diet. Journal of Food Biochemistry, 2014; 38(2), 159-166.

[37] Kakar S A, Tareen R B, Kakar M A, Jabeen H, Kakar S, Al-kahraman Y M S A, \& Shafee M. Screening of Antibacterial Activity of Four Medicinal Plants of Balochistan-Pakistan. Pak. J. Bot, 2012; 44(2010), 245-250.

[38] Sasikumar J M, Thayumanavan T, Subashkumar R, Janardhanan K, \& Lakshmanaperumalsamy P. Antibacterial activity of some ethnomedicinal plants from the Nilgiris, Tamil Nadu, India. Indian Journal of Natural Products and Resources, 2007; 6(1), 34-39.

[39] Irshad A H, Pervaiz A H, Abrar Y B, Fahelboum I, \& Awen B Z S. Antibacterial activity of Berberis lycium root extract. Trakia Journal of Sciences, 2013; 11(1), 88-90.

[40] Rasool S, Khan F Z, Hassan S U, Ahmed M, Ahmed M, \& Tareen R B. Anticonvulsant, antimicrobial and cytotoxic activities of Berberis calliobotrys aitch ex koehne (Berberidaceae). Tropical Journal of Pharmaceutical Research, 2015; 14(11), 2031-2039.

[41] Shahid T, Memon M, Malik R A, Ikram N, Malik W, \& Ali A. A study of Antimicrobial Activity of Berberis vulgaris ( Zirishk ) Aqueous Plant Extract using Pathogenic Isolates from Patients of Islamabad and Rawalpindi. Imperial Journal of Interdisciplinary Research, 2017; 3(5), 1365-1371. 
[42] Malik Z H, Jain K, Ravindran K C, and Sathiyaraj G. In vitro Antimicrobial Activity and Phytochemical Analysis of Berberis. International Journal of Ethnobiology \& Ethnomedicine, 2017; 4(1), $1-6$.

[43] Dashti Z, Shariatifar N, \& Nafchi A M. Study on antibacterial and antioxidant activity of Oak gall Quercus infectoria extracts from Iran. International Journal of Pharma Sciences and Research, 2014; 5(1), 705-708.

[44] Aziz U, \& Choudhary M I. Antibacterial, phytotoxic, insecticidal and cytotoxic potential of Vitex agnus-castus. Journal of Medicinal Plants Research, 2011; 5(23), 5642-5645.

[45] Siddiqui F A, Ahmad M M, Sajid M I, Jamshaid M, Zaman M, Muhammad N, Raza A A, Majeed I, and Khan G J. In-Vitro Antibacterial, Antifungal, Cytotoxic and Insecticidal Activity of Various Fractions obtained from the berries of Berberis baluchistanica. Indo European Journal of Scientific Discovery, 2016; 2(2), 1-6.

[46] Baloch N, Nabi S, \& Al-Kahraman Y M S A. In vitro Antimicrobial, Insecticidal, Antitumor Activities and Their Phytochemical Estimation of Methanolic Extract and its Fractions of Medicago lupulina Leaves. World Applied Sciences Journal, 2013; 23(4), 500-506.

\section{ANNEXER}

Table.4.1 Various Extracts of Berberis royleana

\begin{tabular}{|ll|l|l|}
\hline S. No. & & Extracts / Fractions & Extracted powder in grams \\
\hline 1 & Crude methanol & $106 \mathrm{~g}$ \\
2 & Water & $55 \mathrm{~g}$ \\
3 & $n$-Hexane & $0.7 \mathrm{~g}$ \\
4 & Ethyl acetate & $12 \mathrm{~g}$ \\
5 & Chloroform & $13 \mathrm{~g}$ \\
\hline
\end{tabular}

Table.4.2. Frequency distribution of bacterial isolates

\begin{tabular}{|c|c|c|}
\hline S. No & Bacterial isolates & Number of isolates \\
\hline 1 & Staphylococcus aureus & 16 \\
2 & Escherichia coli & 13 \\
3 & Pseudomonas aeruginosa & 4 \\
4 & Klebsiella pneumoniae & 3 \\
5 & Proteus spp & 3 \\
\hline
\end{tabular}




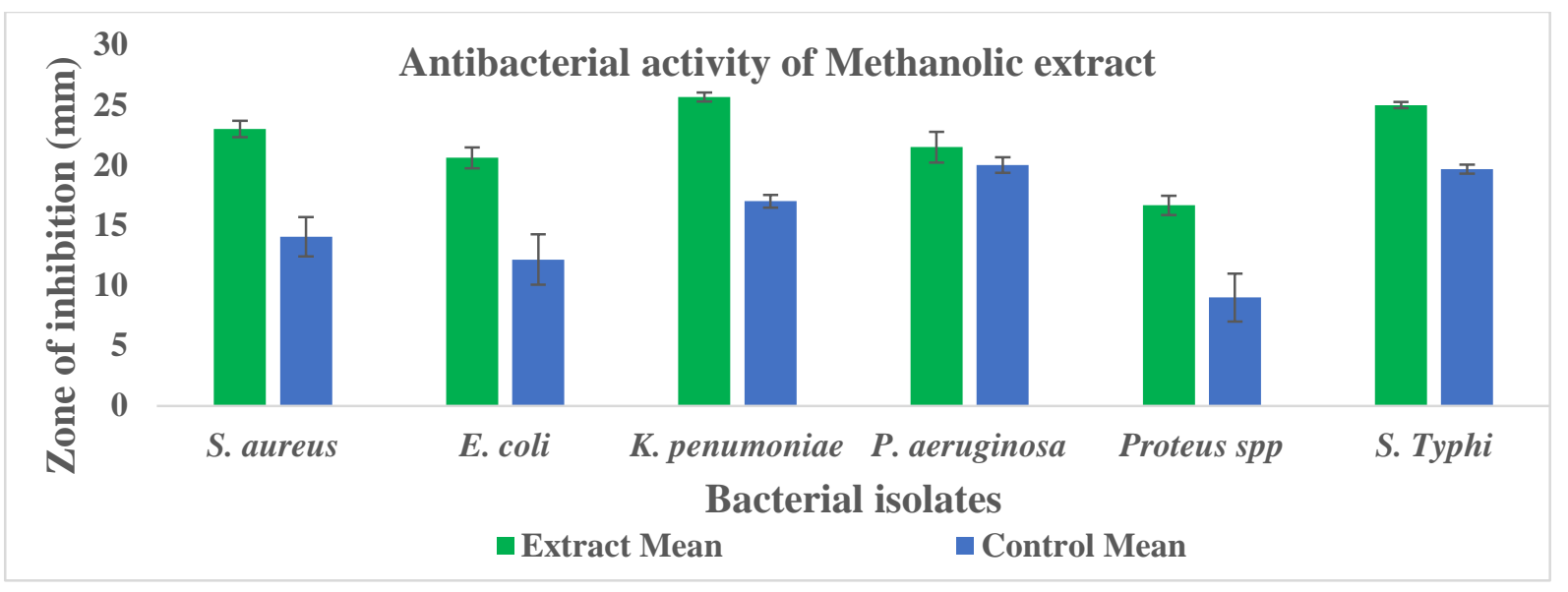

Figure.4.1. Methanol fraction antibacterial activity B. royleana extract

Methanolic extract $100 \mu \mathrm{g}$ and positive control ciprofloxacin $5 \mu \mathrm{g}$

Table.4.3. Methanolic fraction and antibiotic antibacterial activity

\begin{tabular}{|l|l|l|l|}
\hline S. No. & Bacterial isolate & Extract Mean $Z \mathbf{I} \pm$ SD & Control Mean $Z \mathbf{Z I} \mathbf{S D}$ \\
\hline 1 & S. aureus & $23 \pm 2.7$ & $14.1 \pm 6.56$ \\
2 & E. coli & $20.62 \pm 3.4$ & $12.2 \pm 8.36$ \\
3 & K. pneumoniae & $25.7 \pm 1.5$ & $17 \pm 1$ \\
4 & P. aeruginosa & $21.5 \pm 5.1$ & $20 \pm 2.58$ \\
5 & Proteus spp & $16.7 \pm 3.21$ & $9 \pm 7.9$ \\
6 & S. Typhi & $25 \pm 1$ & $19.7 \pm 1.53$ \\
\hline
\end{tabular}

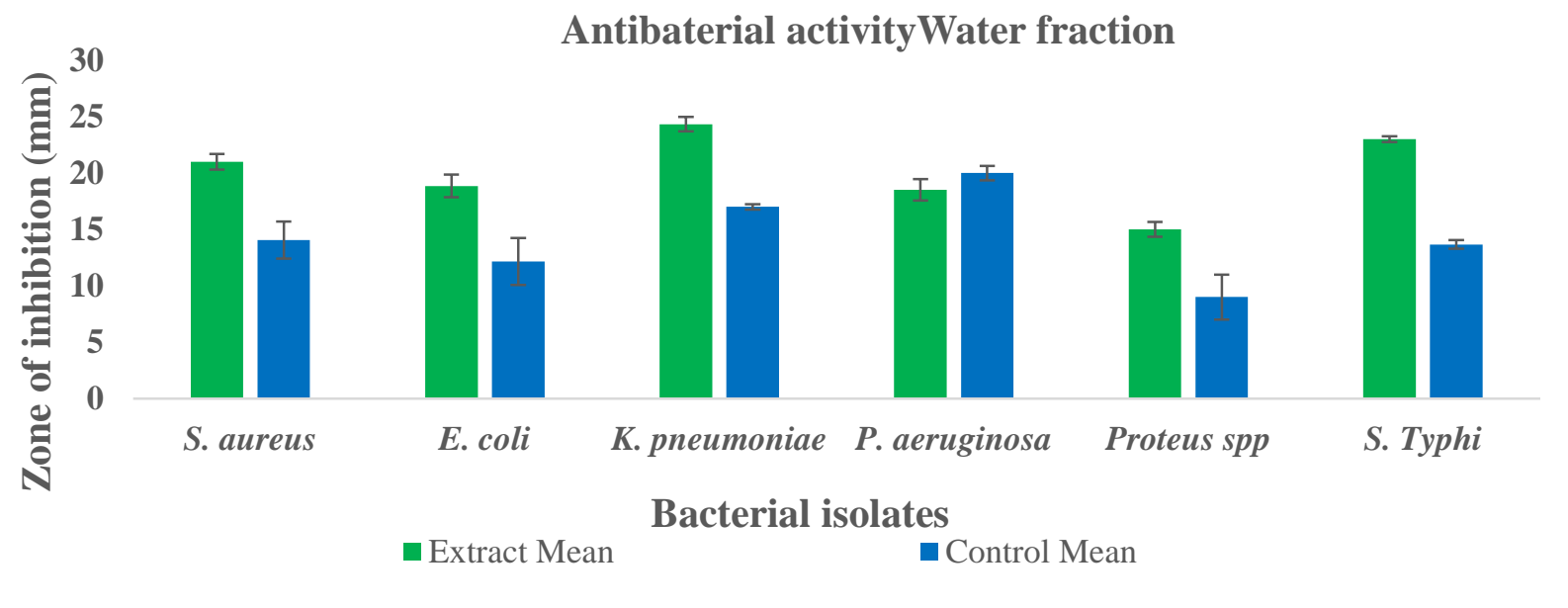

Figure.4.2. Water fraction antibacterial activity of B. royleana extract

Water extract $100 \mu \mathrm{g}$ and positive control ciprofloxacin $5 \mu \mathrm{g}$ 
Table.4.4. Water fraction and antibiotic antibacterial activity

\begin{tabular}{|c|l|l|l|}
\hline S. No & Bacterial Isolate & Extract Mean $Z \mathbf{I I} \boldsymbol{S D}$ & Control Mean ZI \pm SD \\
\hline 1 & S. aureus & $21 \pm 2.8$ & $14.1 \pm 6.6$ \\
2 & E. coli & $18.9 \pm 4.04$ & $12.2 \pm 8.36$ \\
3 & K. pneumoniae & $24.4 \pm 2.5$ & $17 \pm 1$ \\
4 & P. aeruginosa & $18.5 \pm 3.8$ & $20 \pm 2.58$ \\
5 & Proteus spp & $15 \pm 2.6$ & $9 \pm 7.9$ \\
6 & S. Typhi & $23 \pm 1$ & $13.7 \pm 1.53$ \\
\hline
\end{tabular}

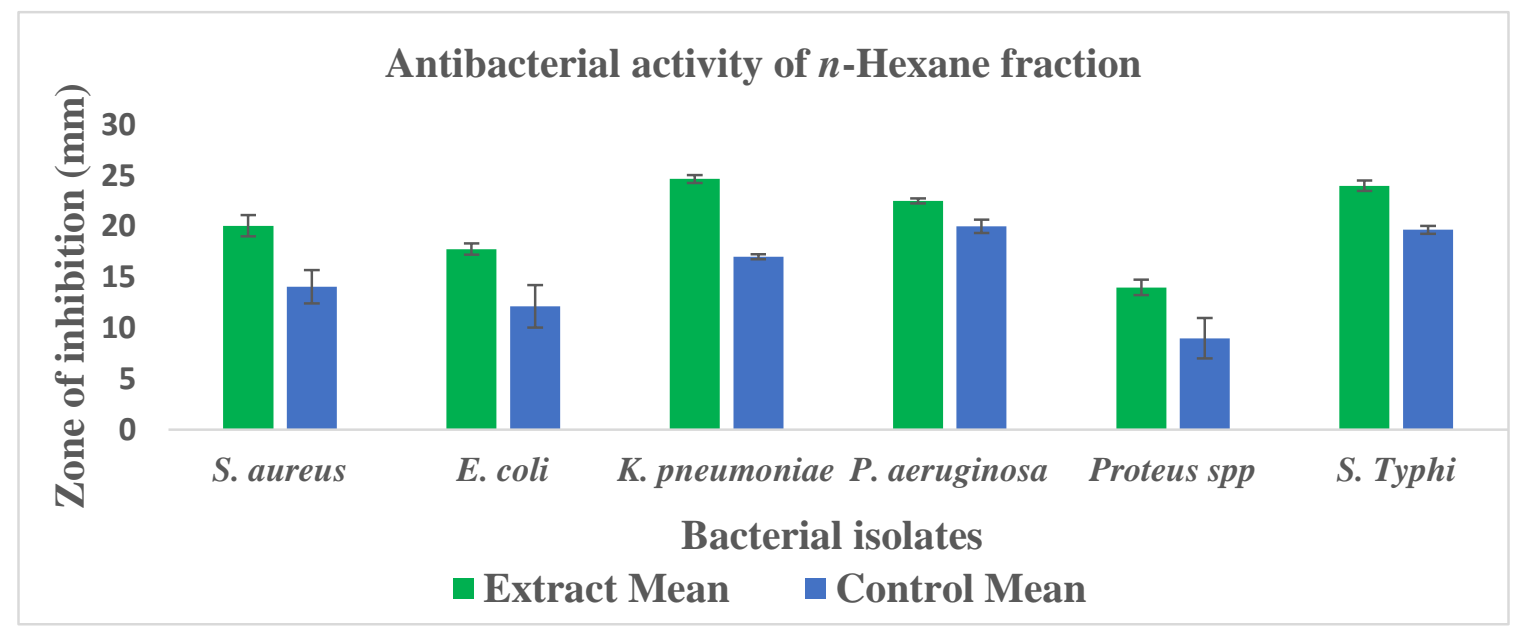

Figure.4.3. $n$ - Hexane fraction antibacterial activity of $B$. royleana extract

$n$-Hexane extract $100 \mu \mathrm{g}$ and positive control ciprofloxacin $5 \mu \mathrm{g}$

Table No.4.5. $n$ - Hexane fraction and antibiotic antibacterial activity

\begin{tabular}{|c|l|l|l|}
\hline S. No & Bacterial isolate & Extract Mean ZI \pm SD & Control Mean ZI \pm SD \\
\hline 1 & S. aureus & $20.1 \pm 4.2$ & $14.1 \pm 6.5$ \\
2 & E. coli & $17.8 \pm 2.16$ & $12.2 \pm 8.36$ \\
3 & K. pneumoniae & $24.7 \pm 1.5$ & $17 \pm 1$ \\
4 & P. aeruginosa & $22.5 \pm 1$ & $20 \pm 2.58$ \\
5 & Proteus spp & $14 \pm 3$ & $9 \pm 7.9$ \\
6 & S. Typhi & $24 \pm 2$ & $19.7 \pm 1.52$ \\
\hline
\end{tabular}




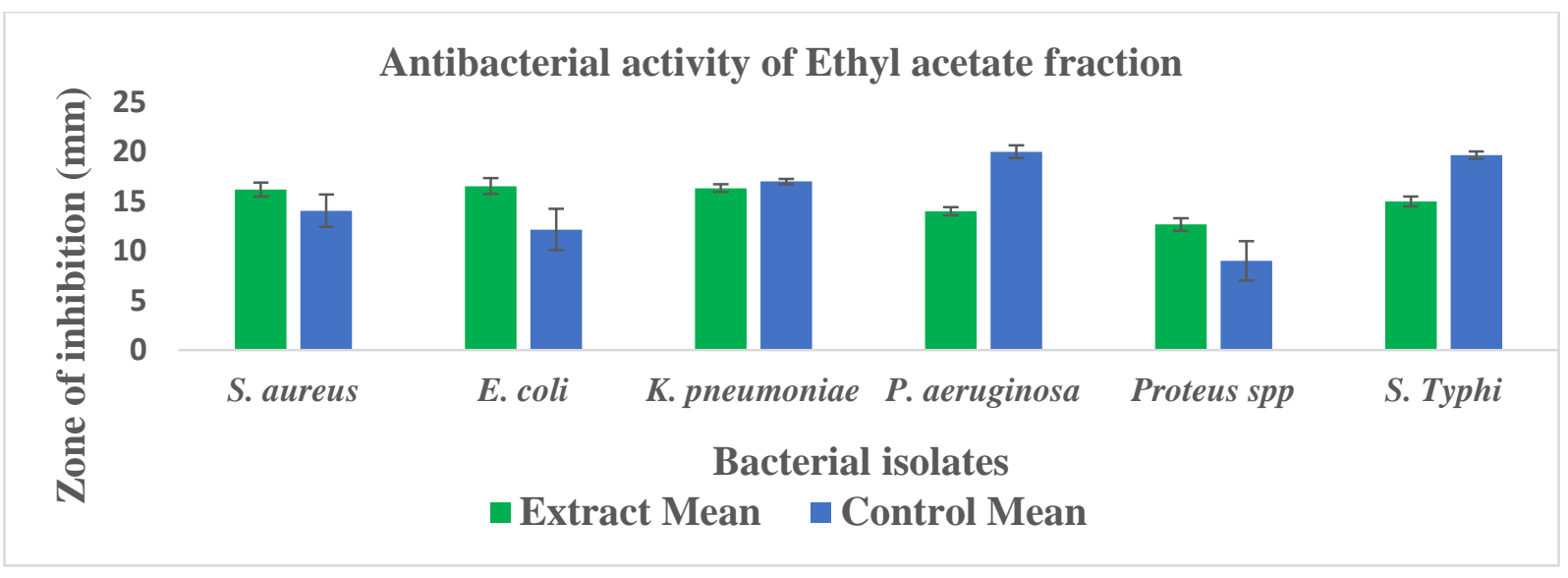

Figure.4.4. Ethyl acetate fraction antibacterial activity of $B$. royleana extract

Ethyl acetate extract $100 \mu \mathrm{g}$ and positive control ciprofloxacin $5 \mu \mathrm{g}$

Table.4.6. Ethyl acetate fraction and antibiotic antibacterial activity

\begin{tabular}{|c|c|c|c|}
\hline S. No & Bacterial Isolate & Extract Mean ZI \pm SD & Control Mean ZI \pm SD \\
\hline 1 & S. aureus & $16.2 \pm 2.85$ & $14.2 \pm 6.56$ \\
2 & E. coli & $16.6 \pm 3.2$ & $12.2 \pm 8.36$ \\
3 & K. pneumoniae & $16.3 \pm 1.53$ & $17 \pm 1$ \\
4 & P. aeruginosa & $14.0 \pm 1.63$ & $20 \pm 2.6$ \\
5 & Proteus spp & $12.7 \pm 2.52$ & $9 \pm 7.93$ \\
6 & S. Typhi & $15.0 \pm 2$ & $19.7 \pm 1.53$ \\
\hline
\end{tabular}

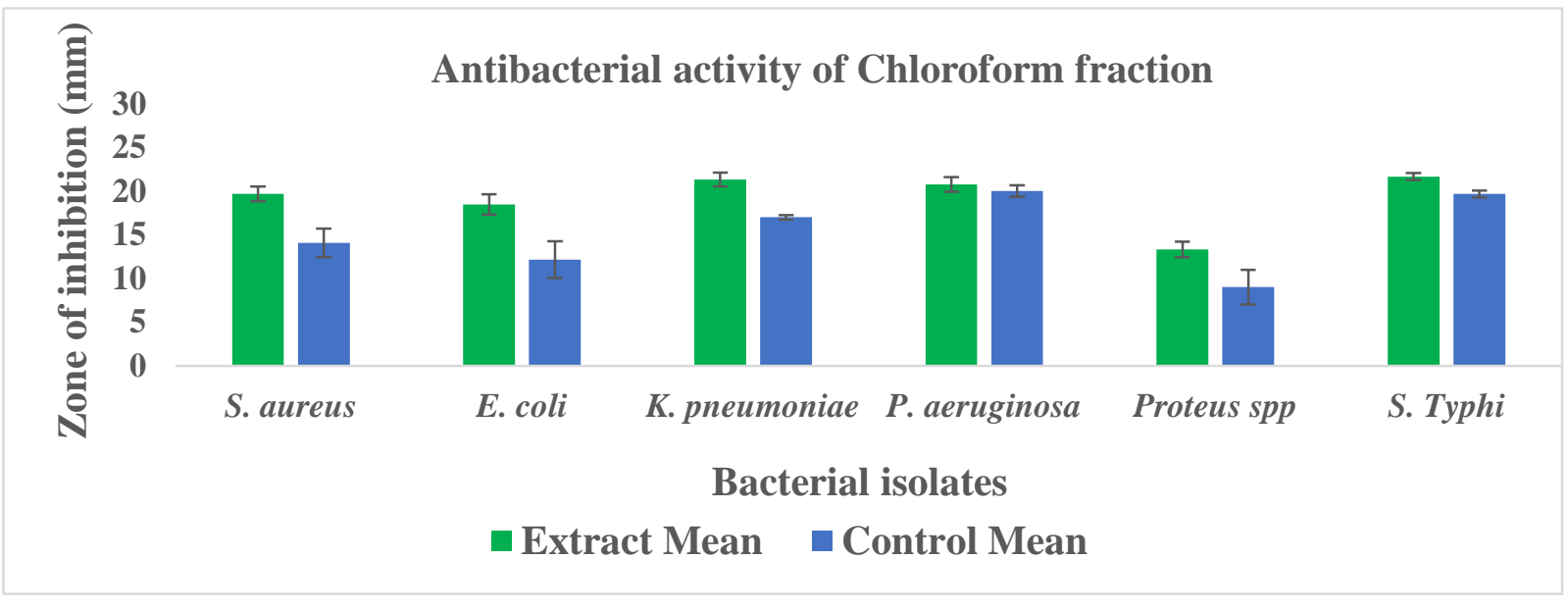

Figure.4.5. Chloroform fraction antibacterial activity of $B$. royleana

Chloroform extract $100 \mu \mathrm{g}$ and positive control ciprofloxacin $5 \mu \mathrm{g}$ 
Table. 4.7. Chloroform fraction and antibiotic antibacterial activity

\begin{tabular}{|c|l|c|c|}
\hline S. No. & Bacterial isolate & Extract Mean ZI $\mathbf{S D}$ & Control Mean ZI \pm SD \\
\hline 1 & S. aureus & $19.7 \pm 3.34$ & $14.1 \pm 6.56$ \\
2 & E. coli & $18.5 \pm 4.64$ & $12.2 \pm 8.36$ \\
3 & K. pneumoniae & $21.3 \pm 3.21$ & $17 \pm 1$ \\
4 & P. aeruginosa & $20.7 \pm 3.4$ & $20 \pm 2.58$ \\
5 & Proteus spp & $13.3 \pm 3.5$ & $9 \pm 7.94$ \\
6 & S. Typhi & $21.6 \pm 1.52$ & $19.7 \pm 1.53$ \\
\hline
\end{tabular}




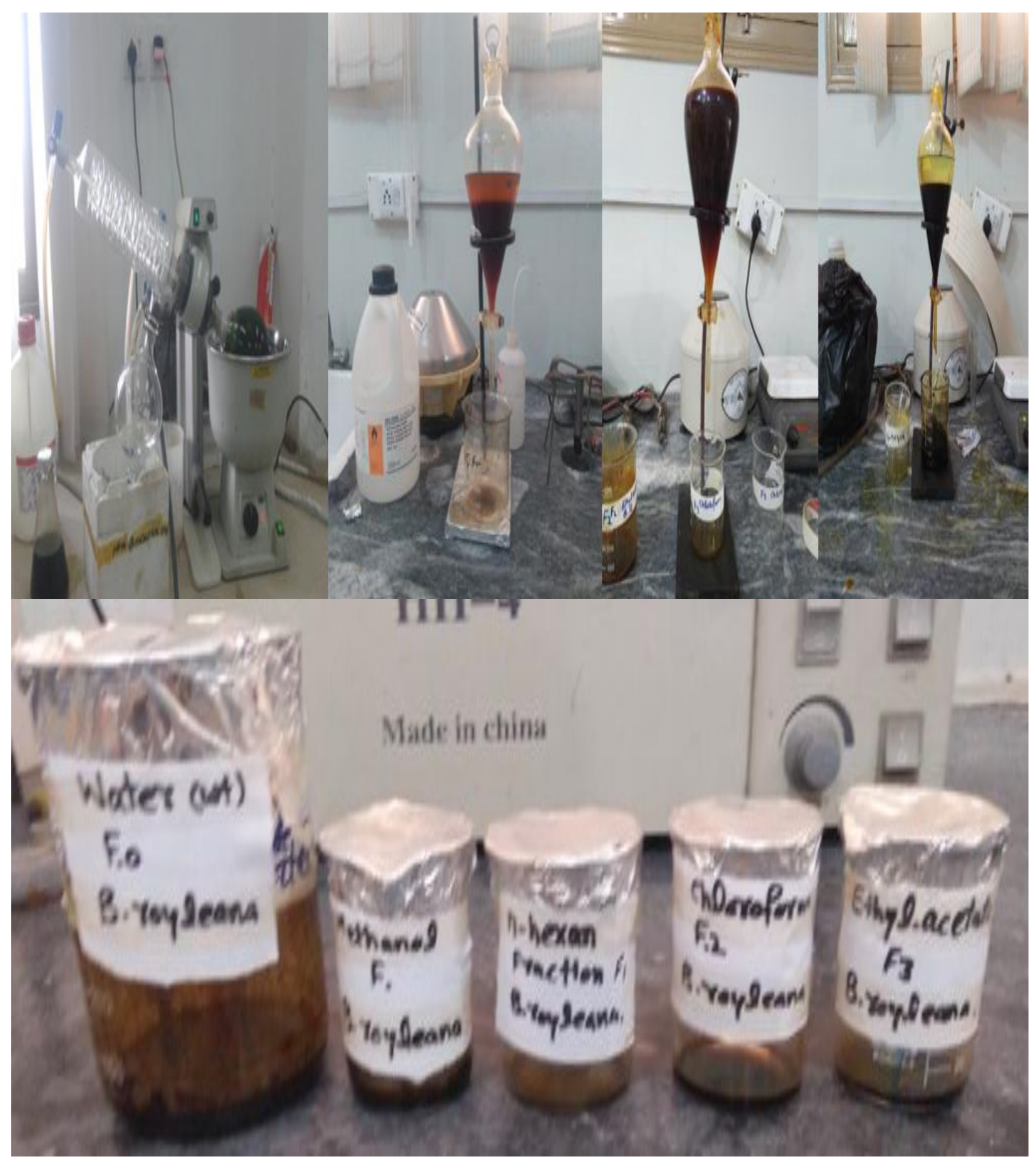

Figure.4.9. Extracts and their fractions of Berberis royleana 

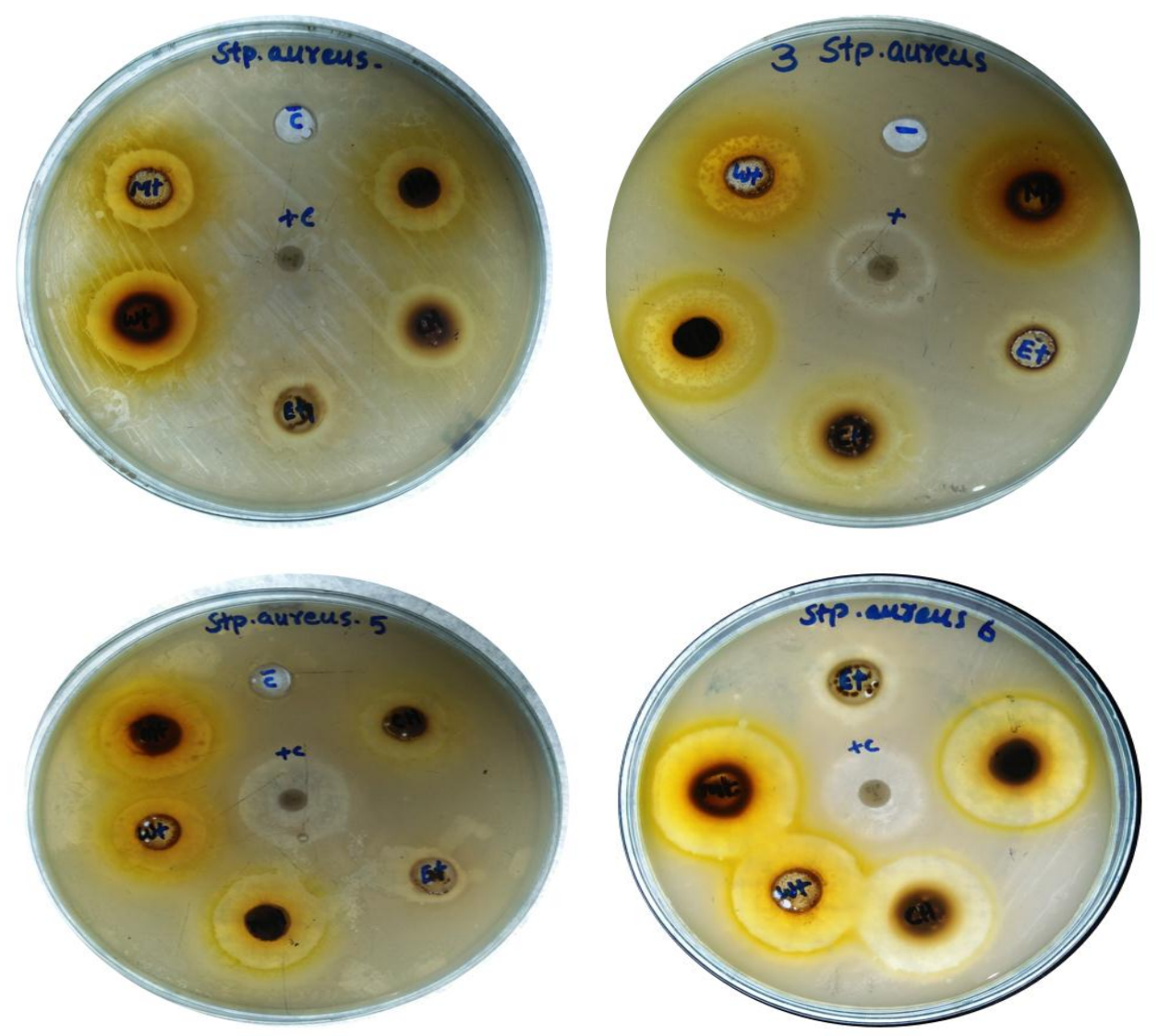

Figure.4.10. Antibacterial activity of $B$. royleana extract against Staphylococcus aureus
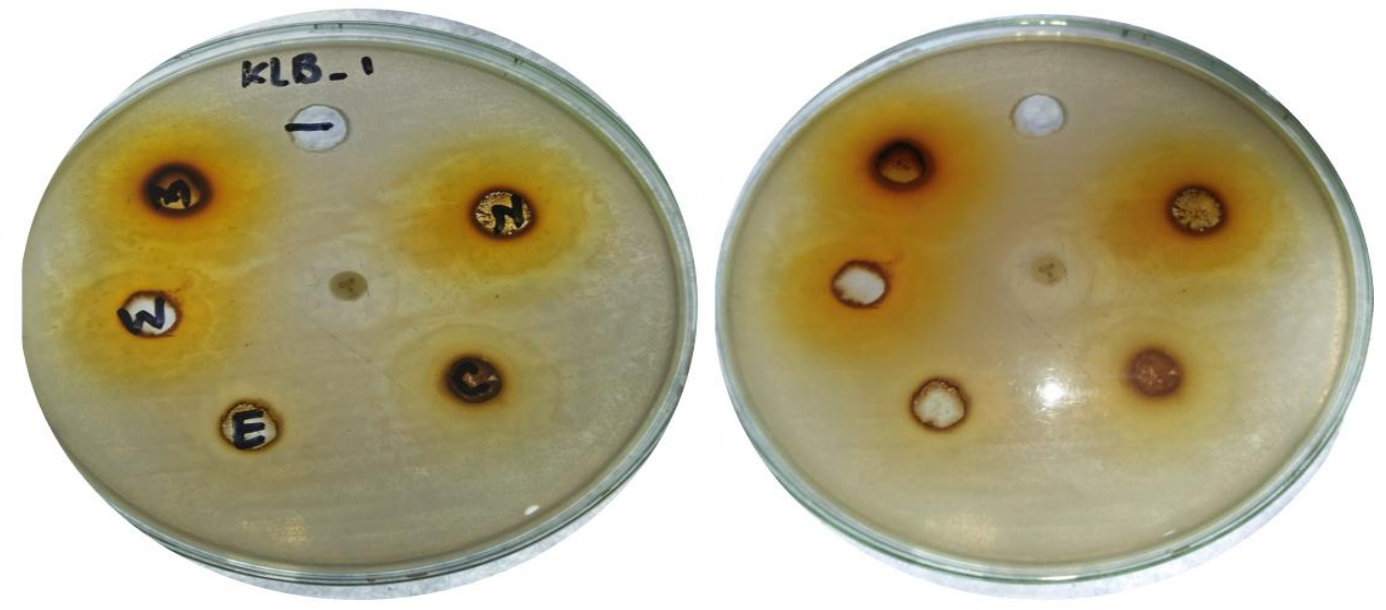

Figure.4.11. Antibacterial activity of $B$. royleana extract against Klebsiella pneumoniae 

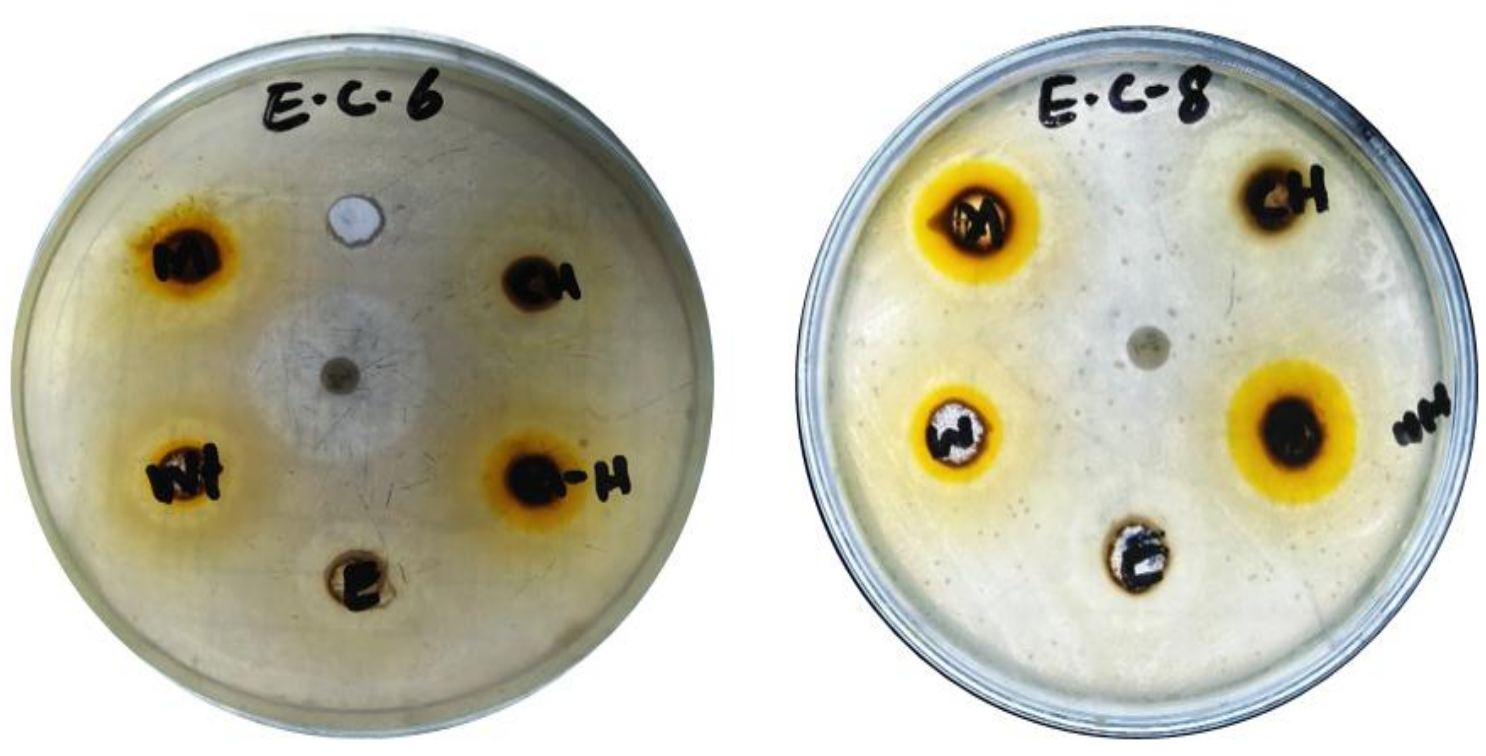

Figure.4.12. Antibacterial activity of $B$. royleana extract against Escherichia coli
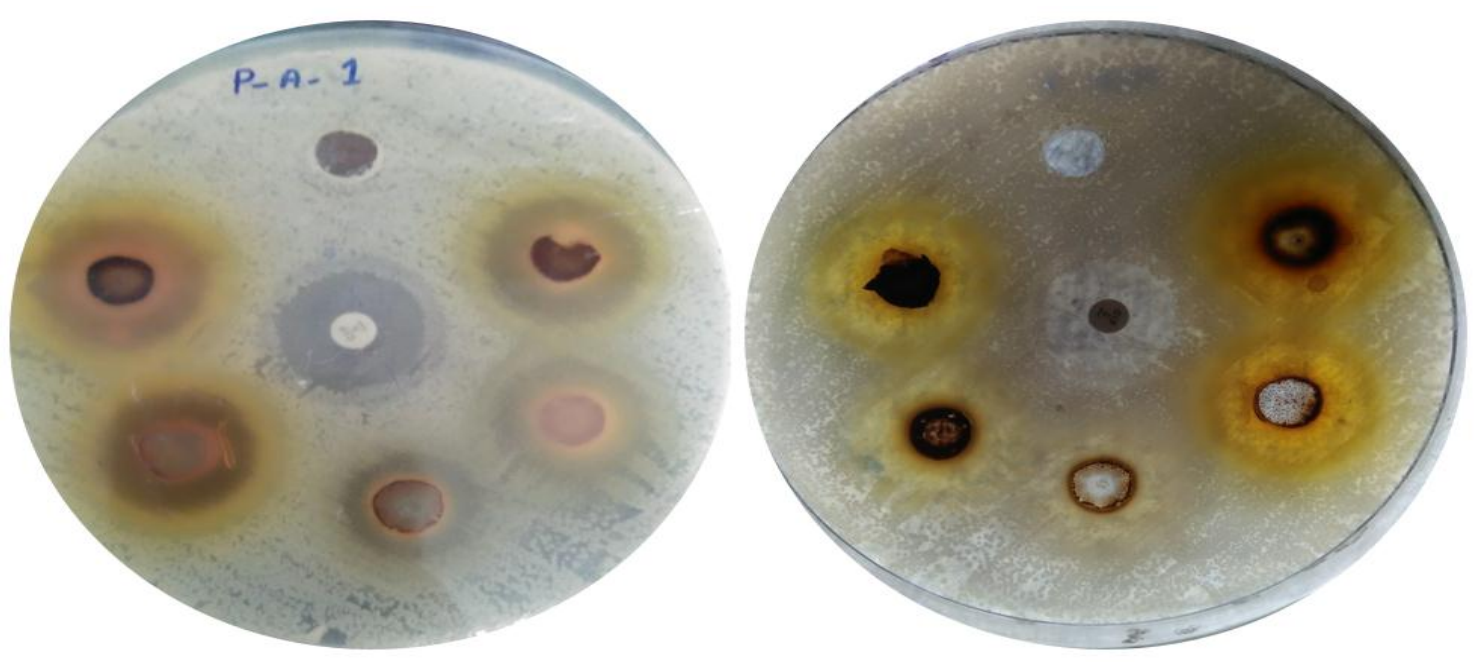

Figure.4.13. antibacterial activity of $B$. royleana extract against Pseudomonas aeruginosa 

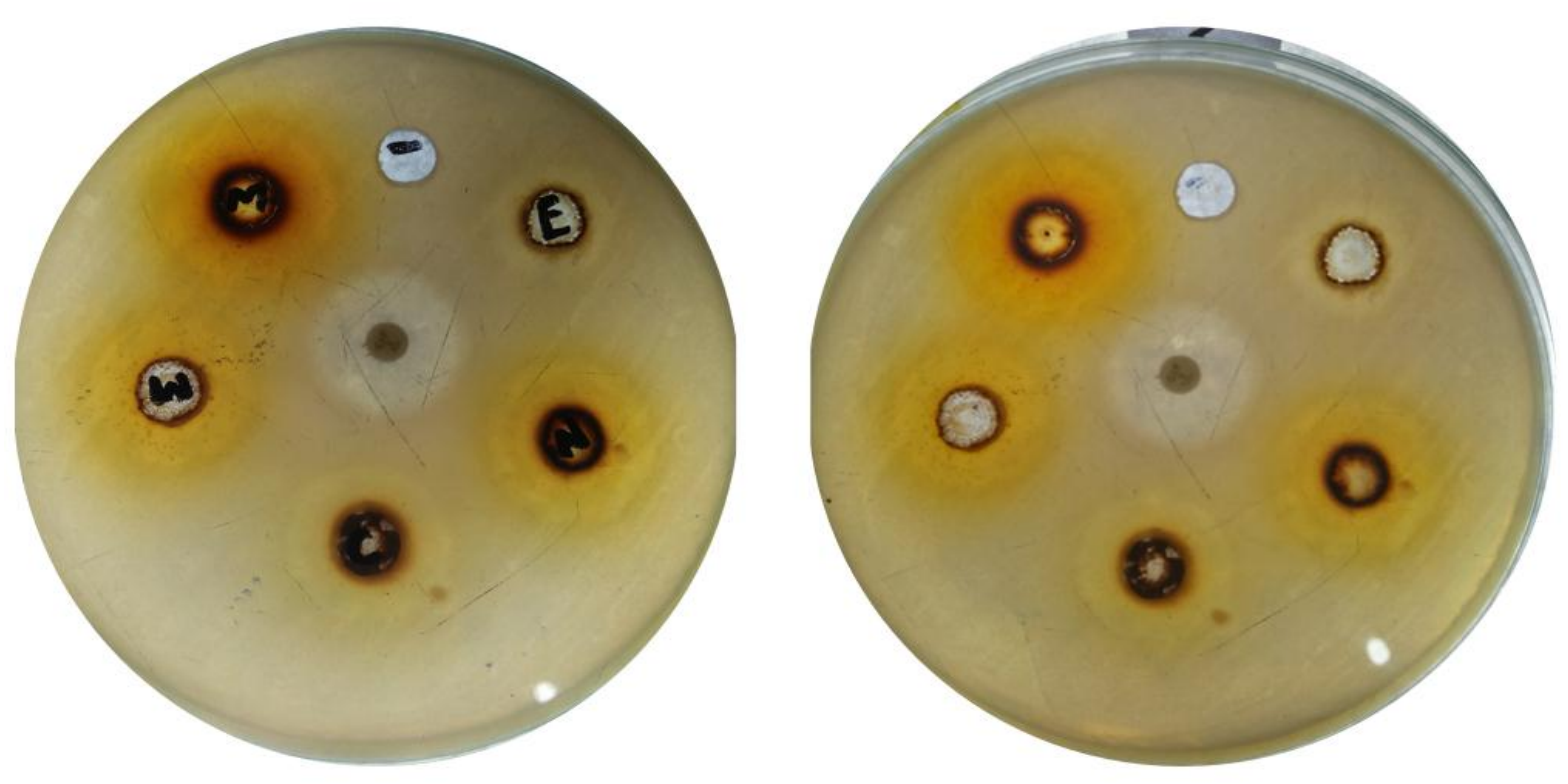

Figure.4.14. Antibacterial activity of $B$. royleana extract against Salmonella Typhi
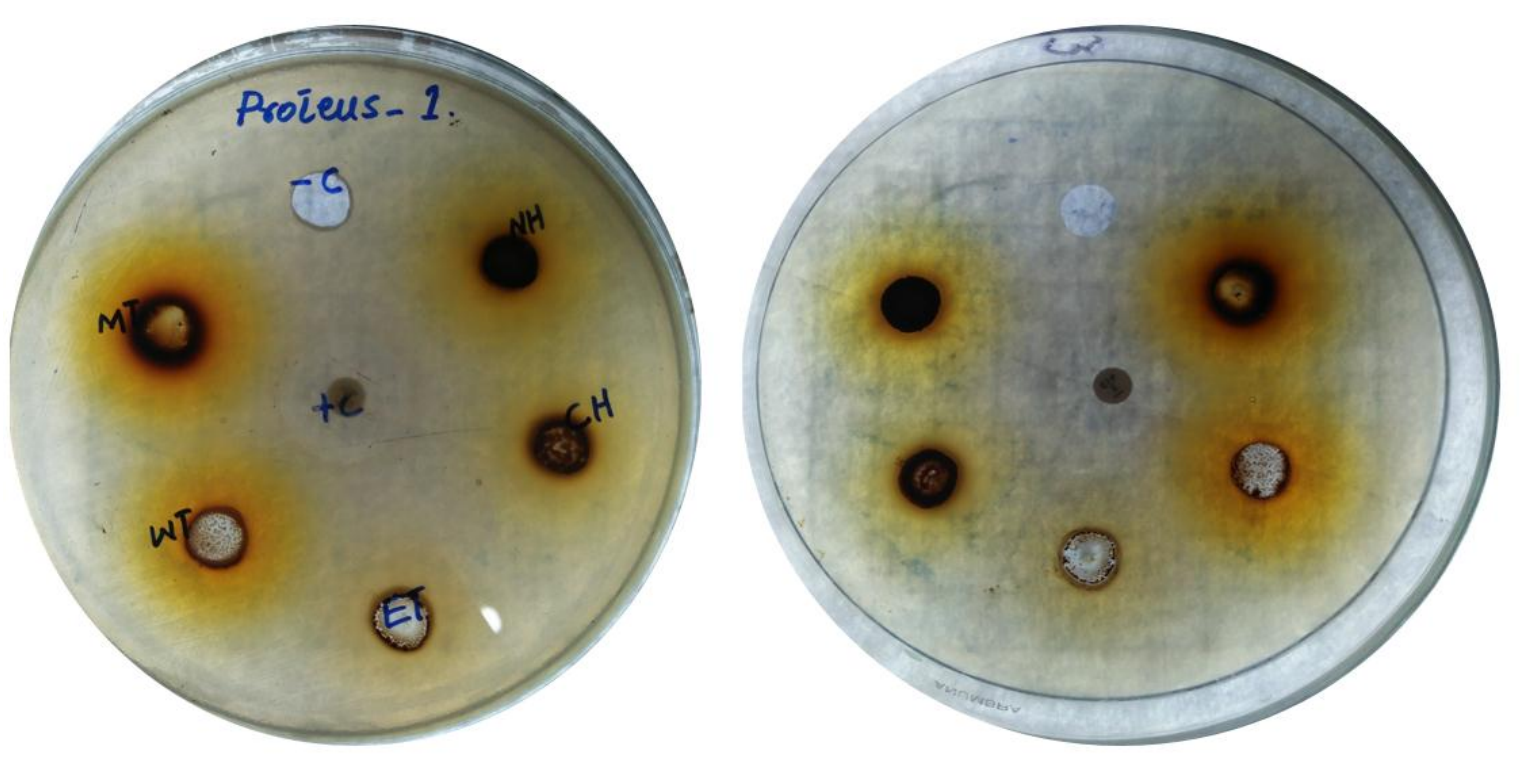

Figure.4.15. Antibacterial activity of Berberis royleana extract against Proteus spp. 